\title{
A memória aflorante de Antonio Candido
}

José Quintão de Oliveira

Doutor em Letras: Literatura Brasileira / UFMG

\begin{abstract}
RESUMO
Análise da escrita memorialística do crítico literário Antonio Candido na busca de localizar os momentos de confluência entre o memorialismo e a crítica literária, considerando-os como uma particularidade dessa escrita e adequada via para o conhecimento do autor e da obra.
\end{abstract}

\section{PalaVRas-CHAVE}

Crítica literária, memorialismo, afloramento memorialístico, digressão, Antonio Candido

\section{INTRODUÇÃO}

Desde os seus primórdios a obra ensaística de Antonio Candido vem sendo percorrida por um veio memorialístico que de certa maneira a distingue. A partir da morte de Mário de Andrade começam a surgir textos que rememoram episódios da história recente do país de que foi testemunha, fatos relacionados à fundação da Universidade e à trajetória do grupo da revista Clima e ainda companheiros da atividade política, professores, alunos, amigos diversos, familiares, etc.. Devem ser mencionados também os seus escritos sobre o tema, os prefácios e as resenhas de recepção a obras memorialísticas. Há ainda inúmeros estudos sobre escritores fortemente marcados pelo motivo da memória, como Proust, Graciliano Ramos, José Lins do Rego, Carlos Drummond de Andrade e Pedro Nava, entre muitos outros, além de reflexões sobre o memorialismo e a literatura pessoal em sentido mais amplo. Aliás, "literatura pessoal” é um termo-chave usado pelo próprio Candido ${ }^{1}$ para se referir àquela escrita marcada pelos motivos da

\footnotetext{
${ }^{1}$ CANDIDO. A educação pela noite, p. 64.
} 
memória e da autobiografia nas suas mais diversas manifestações. Merecem ser lembradas ainda as dezenas de entrevistas que ao longo da carreira concedeu a jornalistas, pesquisadores, estudantes, além dos diversos depoimentos gravados ou escritos. Seria importante lembrar o empenho demonstrado pelo crítico na reivindicação de uma leitura de corte memorialístico para diversos dos seus escritos críticos e teóricos. Não se esgota aí, porém, esse veio que deixa marcas mais profundas na sua escrita crítica, como se intenta mostrar.

Em certo momento da trajetória intelectual desse crítico ocorre um estreitamento de laços entre escrita crítica e memorialismo no seu ensaísmo, como é perceptível no livro Teresina etc. A partir desse livro, lançado em 1980, seu olhar sobre o mundo é, acima de tudo, autorreflexivo, produzindo ensaios históricos e balanceando a própria produção acadêmica. Em consequência publica trabalhos que durante décadas relutara em levar a público - tais como as anotações de aulas reunidas em $O$ estudo analítico do poema, publicado em 1987, e Noções de análise histórico-literária, em edição bem posterior, já de 2005 -, acedendo à argumentação de pares seus quanto à importância documental dos textos e reconhecendo-os apenas como amostra de um jeito de ensinar que ficara no passado. Não parece descabido anotar esse período de sua biografia como caracterizado pelo memorialismo, que, mesmo tendo surgido antes na sua obra e projetando-se nos anos posteriores, marca os anos de 1980 a partir do livro com que abriu essa década.

Posteriormente, em livros como Recortes e $O$ discurso e a cidade, particularmente no primeiro, ocorre um adensamento do que vinha há muito solicitando presença no texto ensaístico, dando uma espécie de nova inflexão à escrita, que cada vez mais se volta para a memória, tornando explícito mesmo ao olhar não muito atento uma das suas características que poderiam ser ditas matriciais, que vinham se apresentando nos livros do autor desde 1959, com $O$ observador literário, passando por A educação pela noite até alcançar aquelas obras. Esses escritos memorialísticos são - na sua maioria, mas não na sua totalidade - textos de circunstância, como os considera o autor e leitores como Murilo Marcondes Moura² e Antônio Arnoni Prado. ${ }^{3}$ Porém, tomados em conjunto, além de constituírem uma parte expressiva da sua produção, prolongam-se no tempo e constituem um importante aspecto da sua escrita. Atentar ao seu memorialismo permite sondar-lhe a concepção de mundo e do fazer literário e permite ainda

\footnotetext{
${ }^{2}$ MOURA. Circunstâncias e intersecções.

${ }^{3}$ PRADO. Significação de Recortes.
} 
acompanhar aspectos relevantes da trajetória intelectual do autor tanto quanto da história cultural do país no século 20.

\section{Percursos memorialísticos}

Na verdade, como já se disse, o motivo da memória se apresenta na escrita de Candido desde os textos iniciais nos já longínquos anos de 1940. De maneira discreta vem se insinuando, suave e impositivamente marcando a sua presença e emergindo às vezes de modo surpreendente em meio ao ensaio crítico, ou substituindo-o quase que integralmente como ocorre principalmente em relação a Oswald e ou Mário de Andrade. Mas não só. Esses afloramentos da memória, tão característicos, parecem um fenômeno bem específico do seu modo de fazer crítica literária e são, certamente, merecedores de um olhar mais atento. Talvez o olhar sobre esse fenômeno particular permita compreender mais amplamente esse crítico. O termo afloramento é tomado aqui no seu sentido mais comum, relacionado à geologia: "Emergência de um veio à superfície da terra; a extremidade desse veio”, conforme a lição do dicionário de Caldas Aulete. Assim como o veio emerge à superfície do solo, revelando o que a terra oculta, a memória aflora no texto crítico de Antonio Candido, modificando-o e revelando travejamentos ocultos pela escrita. Essas emergências memorialísticas não são sempre a mesma coisa; têm razões, objetivos e consequências diversas, repercutindo de variadas formas nos diversos textos em que ocorrem.

Os afloramentos no interior do ensaio crítico não são casuais nem gratuitos. Tome-se por exemplo o ensaio “Jagunços mineiros de Cláudio a Guimarães Rosa”, do livro Vários escritos, em que a memória opera sobre o texto literário duplamente. Primeiro dá-lhe direção e sentido, pois o leitor sente que todo o ensaio crítico, num itinerário de duzentos anos, se torna, com essa presença, um corpo construído para acamá-la; secundariamente, introduz o próprio memorialista no universo do jaguncismo, para em seguida - milagre dos milagres - vinculá-lo ao próprio protagonista do Grande sertão: veredas.

Os jovens de agora não supõem que, ainda há bem pouco, a umas duas ou três centenas de quilômetros das suas salas de aula, passavam-se coisas e movia-se gente como as que narra a literatura evocada nestas palestras. $\mathrm{E}$ acho que não cumpriria nelas a minha tarefa se, entrando um pouco no campo das recordações, não desse o meu próprio testemunho a respeito. ${ }^{4}$

\footnotetext{
${ }^{4}$ CANDIDO. Vários escritos, p. 123.
} 
O trecho acima, do ensaio referido, abre, na parte final, uma digressão em que Candido recorda a própria infância, no sul de Minas, enriquecendo o ciclo de quatro aulas que completava como parte de um curso sobre cangaço na realidade brasileira, ofertado por José Aderaldo Castello. Sem dúvida, o tom pessoal do depoimento traz para próximo dos estudantes, em ambiente urbano na rica, industrializada e cosmopolita São Paulo, uma realidade que logo ali, bem próximo deles, não estava ainda, na verdade, totalmente desaparecida. Basta lembrar que sequer ainda se haviam completado trinta anos da morte de Virgulino Ferreira da Silva, o Lampião, e que muitos dos antigos chefes de "volantes" como aquelas lembradas no ciclo de palestras estavam ainda ativos como policiais de patente elevada, em diversas polícias estaduais, inclusive em Minas Gerais. Deve ser destacado ainda no trecho citado, para além do propósito testemunhal, um empenho em obter uma direta vinculação da literatura à vida, sem rebaixar a arte à condição de puro documento.

No prefácio que escreveu para o livro As ciências no Brasil, de Fernando de Azevedo, há um momento em que Candido se deixa dominar pela recordação e registra que:

Fui aluno e, em seguida, durante dezesseis anos, colaborador de Fernando de Azevedo na Universidade de São Paulo. Durante trinta e tantos anos, até a sua morte, fomos amigos fraternais, apesar da diferença de idade. Lembro bem do seu esforço no preparo e realização deste livro, e nunca esquecerei a intensidade com que acreditava nas ideias sobre as quais o baseou. ${ }^{5}$

A esse pequeno trecho compete o papel de introduzir uma nota pessoal num texto que sem ele, no molde sobriamente acadêmico em que é vazado, seria frio e formal, falando da vida e dos feitos de mais um acadêmico já morto. Ao recordá-lo na sua condição de chefe, companheiro dos afazeres universitários e fraternal amigo, Candido aproxima-o de si, distinguindo-o do rol dos mortos ilustres - afinal, trata-se do amigo daquele que se dirige ao leitor - e humaniza-o ao retirá-lo da fria distância imposta pela morte aconchegando-o com o manto da amizade, que só amplia o respeito manifestado pelo prefaciador e, dessa forma, partilhado pelo leitor. Por esse meio aproximam-se todos e o morto revive pela memória antes de reviver pelo seu legado intelectual ao qual o leitor é apresentado.

Num pequeno texto sobre Vinicius de Moraes, Candido sumaria a produção literária do poeta desde o primeiro livro; a certo momento ocorre: "Numa tarde de domingo ele nos leu

\footnotetext{
${ }^{5}$ CANDIDO. Prefácio, p. 8.
} 
inteiro, o livro ainda inédito; e aliás teria sido preciso vê-lo naquele tempo (...) não se espantando de nada e fazendo da sua poesia um espanto permanente de tudo.”6 Essa digressão, a qual se seguirá outra, intervém fortemente no texto alterando em rememoração o que era aparentemente um roteiro literário, reconfigurando como experiência de vida o que até então se apresentava apenas como experiência de leitura.

Em outro texto dedicado ao poeta, Candido esclarece alguns dos dados memorialísticos com que trabalha no texto acima, lembrando que tomou conhecimento do poema "Balada do mangue” ainda antes da publicação do livro Poemas, sonetos e baladas, que o contém. O livro seria editado em 1946, pela Editora Gaveta, do pintor Clóvis Graciano.

Em 1943 Vinicius de Moraes veio a São Paulo entregá-lo ao editor e nessa condição fez dele uma leitura completa na casa de Lauro Escorel, na rua Manuel da Nóbrega, presentes apenas os donos da casa e eu. Lembro do impacto causado em nós três por este e outros poemas do livro, que marcou o amadurecimento do poeta. ${ }^{7}$

No mesmo texto o crítico lembra que outro poema incluído no livro - Rosário -, "Vinicius contava a sua iniciação sexual, com a naturalidade lírica e tranquila que, na sua obra, purifica qualquer tema ou qualquer palavra, por mais crus que sejam.”» Essa afirmação, que em outra circunstância seria entendida como uma interpretação do poema, vinculando numa só entidade o ser poético e o poeta, parece perder essa condição dada a condição memorialística do texto, que assim transfere ao poeta a responsabilidade pela reivindicação do caráter autobiográfico do poema. Não signifique isso que a reivindicação anula a separação dos dois entes, anula, porém, o caráter meramente interpretativo da afirmação do crítico, modificando drasticamente o texto (ou a sua leitura), portanto.

O último livro de Candido, O albatroz e o chinês, recolhe um pequeno ensaio intitulado Pio Lourenço de Oliveira, carinhoso perfil de um culto e originalíssimo fazendeiro de Araraquara, interior de São Paulo, primo e grande amigo de Mário de Andrade, que o chamava afetuosamente “Tio Pio” e em sua chácara de Araraquara escreveu Macunaíma, conforme o leitor fica sabendo em outro texto recolhido no mesmo livro.

\footnotetext{
${ }^{6}$ CANDIDO. Observador literário, p. 104.

${ }^{7}$ CANDIDO. Um poema de Vinicius de Moraes, p. 71.

${ }^{8}$ CANDIDO. Um poema de Vinicius de Moraes, p. 71.
} 
Pio Lourenço, que é 1875, tinha dezoito anos quando Mário nasceu, em 1893, e dadas as relações de família, reforçadas pelo casamento com Dona Zulmira em 1897, conviveu com ele a vida toda, vendo-o nascer, crescer e tornar-se um dos maiores escritores do Brasil. quase naturalmente, passou para ele a amizade que teve pelo pai, e como ambos eram apaixonados pelos estudos e a literatura, formaram vínculos duradouros e firmes. ${ }^{9}$

Parece mais que explicada a sua presença na ensaística do crítico: afetivamente ligado a Mário de Andrade, envolvido com assuntos culturais e figura humana das mais fascinantes, acabou por atrair-lhe o olhar. Leia-se, porém, um parágrafo do prefácio que Candido escreveu em 1964 para o livro Parceiros do Rio Bonito:

Não posso deixar de lembrar, com saudade e reconhecimento, o meu velho amigo Pio Lourenço Corrêa, falecido em 1958, admirável tipo de fazendeiro paulista, culto e reto, que me acolheu várias vezes na sua chácara dos arredores de Araraquara, e a quem devo muito do que percebo da cultura rústica. A sua conversa era uma lição constante; a sua experiência, imensa; a sua memória, prodigiosa. Erudito e estudioso da língua e das ciências naturais, caçador e investigador dos costumes; conhecedor minucioso da flora, da fauna e da técnica rural, devo-lhe mais do que poderia registrar, porque são coisas que se incorporam ao modo de ver e de sentir. Quando ele desenterrava das recordações de setuagenário o que contara na infância um velho pai setuagenário, parecia-me tocar no vivo o século XVIII de Araritaguaba, onde sua avó falava língua-geral e cuja tradição ele mantinha, na escarpada austeridade do seu caráter. ${ }^{10}$

Certamente, esse trecho é mais que suficiente para desvelar, por trás do distanciamento sobre que se constrói a afetividade do ensaio de 2002, a memória. Isso num texto que ao leitor desavisado se apresentava como de interesse puramente literário, fruto da admiração por um escritor e pesquisador provinciano afetivamente próximo a uma admiração literária e humana. No caso do ensaio dedicado a Vinicius, a re-significação ocorre pela intervenção de um trecho memorialístico no corpo do texto; relativamente a Pio Lourenço, a mudança se dá pela intervenção de outro texto.

Como se viu, o texto crítico em que aflora o memorialismo é por este modificado, ao mesmo tempo que o reconfigura ao conferir-lhe o temperamento indagador característico do ensaio crítico. Ou seja, da mesma forma que esses afloramentos operam sobre os textos em que surgem, pode-se imaginar que a memória caracteriza e reconfigura a totalidade do criticismo de

\footnotetext{
${ }^{9}$ CANDIDO. Observador literário, p. 119.

${ }^{10}$ CANDIDO. Os parceiros do Rio Bonito: estudo sobre o caipira paulista e a transformação dos seus meios de vida, p. 15.
} 
Antonio Candido a partir das marcas que vai lhe impondo. Tome-se como exemplo o que diz num prefácio: “Confesso que a leitura me fez voltar quase insensivelmente às experiências de moço"; ${ }^{11}$ com esses termos o crítico introduz quatro sólidos parágrafos de rememoração, em que atribui à leitura o papel de uma espécie de gatilho das recordações. O prefaciador esclarece desde o princípio que a recordação não é gratuita, mas o caminho para a busca de "um primeiro esclarecimento por meio dessa forma precária mas viva de conhecer que é a impressão pessoal”. ${ }^{12}$ Esse esclarecimento metodológico se dá no corpo de uma rememoração do convívio com colegas e amigos integralistas nos anos de 1930, em Poços de Caldas e depois em São Paulo. Não se esgotam, porém, na lembrança; esta é apenas um caminho para tentar compreendê-los e adequadamente situar historicamente o movimento político a que se filiavam.

Resumidamente, em quatro sucintos parágrafos, Candido mostra como é possível tornar a experiência pessoal em instrumento de conhecimento. Acima de tudo, mostra-a como um caminho auxiliar na aceitação do outro e no estabelecimento da empatia como necessário caminho para aquisição desse mesmo conhecimento. Na mesma medida estabelece a necessidade fundamental do reconhecimento da legitimidade do pensamento adverso, mesmo quando esse, olhado retrospectivamente, se mostra historicamente incorreto e politicamente inadequado. E conclui: “Assim, mesmo partindo da mera experiência pessoal bem sei quanto é preciso pensar com objetividade, ter o senso dos matizes e calcular a força especificadora das condições históricas.”13 Dotado dessa competência, o indivíduo se torna capaz de fazer com que a memória funcione como método de conhecer o mundo.

Os prefácios constituem mesmo um caso especial nessa relação entre crítica e memória. Na verdade acabam servindo para lembrar que qualquer tentativa de classificação será sempre provisória e insuficiente. Tome-se para exemplo um pequeno texto na abertura da edição crítica de Perto do coração selvagem, preparada por Benedito Nunes e publicada nos Archives da Unesco. É um curto prefácio - no livro chamado 'Liminar” -, aparentemente comum, em que o crítico reporta o lançamento da obra, a primeira da autora, em 1943. Uma coisa, porém, terá desde o início chamado a atenção dos conhecedores do criticismo de Candido: a sua relação especial com a obra e sua autora, já que foi um dos pioneiros na sua recepção crítica, tendo sido

\footnotetext{
${ }^{11}$ CANDIDO. Teresina etc., p. 112.

${ }^{12}$ CANDIDO. Teresina etc., p. 112.

${ }^{13}$ CANDIDO. Teresina etc., p. 113.
} 
capaz de acolher adequadamente a escritora que surgia, não obstante a perplexidade que demonstra diante do texto. Assim, a recuperação do ambiente literário em que "Clarice Lispector instaurava as aventuras do verbo, fazendo sentir com força a dignidade própria da linguagem”, ${ }^{14}$ destacando outras obras transformadoras que surgiram à época, pode ser um ato meramente crítico, mas que se impõe como rememoração, com tal força que o próprio crítico termina por sucumbir ao avassalamento imposto pela memória, o que o leva a fazer o que raramente o leitor encontra na sua escrita: uma autocitação, trazendo à cena um texto seu sobre a autora.

Esses índices podem ser tomados como um estímulo à reflexão sobre a condição mesma da digressão no interior do criticismo de Antonio Candido. Pois, se pode ocorrer um avassalamento da escrita pela memória, o leitor deve atentar para presença de uma digressão motivada, isto é, o pensamento digressivo deliberadamente construído como recurso didático uma espécie de pedagogia da digressão. Deve-se atentar ainda para a possibilidade da sua presença como recurso retórico ou estilístico. Parece ser o que se dá no ensaio Uma palavra instável, recolhido no livro Vários escritos, que discute o nacionalismo a partir das flutuações sofridas por essa palavra ao longo do processo histórico. O texto trata de um tema político e acadêmico, bem pouco vinculado à afetividade e ganha, a certa altura, caráter digressivo. Não se trata de um texto oral ou destinado à oralização, mas de ensaio formal, escrito para um livro temático coletivo. Claro está que nem sempre há essa transparência, por mais preparado que se apresente o leitor, nem sempre este conseguirá fazer a distinção, localizando a motivação de cada manifestação do discurso digressivo. Cabe-lhe unicamente ser crítico e reflexivo, sabendo de antemão que nem tudo se oferece limpidamente à análise.

O livro A educação pela noite guarda um ensaio ao qual se pode produtivamente prestar alguma atenção. Trata-se de uma palestra pronunciada na Biblioteca Municipal de São Paulo, em 1978, em homenagem a Sérgio Milliet; devidamente publicada no boletim daquela Instituição, foi também incluída como prefácio na reedição do Diário crítico. Finalmente chega à obra que o acolhe, que recebeu sua condição definitiva na quinta edição revista pelo autor, de 2006, quase trinta anos e oito edições depois da sua primeira apresentação pública. Pode ser considerada como obra que atingiu seu ponto máximo de elaboração, representativa do pensamento e do modo de fazer crítica literária do seu autor. Não se explorará aqui esse ensaio dedicado ao amigo e mestre, por desnecessário, mas fique registrado como um entre vários exemplos, que ali se vê

\footnotetext{
${ }^{14}$ CANDIDO. No começo era de fato o verbo, p. XVIII.
} 
funcionando em plena potência essa espécie de verdadeira instituição do criticismo de Antonio Candido.

\title{
ÚLTIMAS PALAVRAS
}

Este estudo partiu da ideia de estudar o memorialista tanto quanto o crítico literário, tentando localizar aqueles momentos em que essas duas instâncias da vivência intelectual de Candido se sobrepõem, se completam ou se esclarecem reciprocamente. Parece não ser arbitrário concluir que a ocorrência dessas peculiares manifestações do memorialismo é mais um índice da força da expressão ensaística na relação deste crítico com o conhecimento. Afinal, o que pode ser mais caracteristicamente ensaístico que a digressão memorialística? Há que se destacar ainda a capacidade que têm esses momentos de imbricação entre ensaio e memória de vincular literatura e vida. Ao substituir a simples exposição didática ou reflexiva por um depoimento pessoal, o autor traz à superfície do seu texto essa relação de contiguidade - de unidade, talvez seja a melhor expressão - entre essas duas instâncias, que o estudo metódico tende muitas vezes a separar. Em outras palavras, o afloramento memorialístico e o discurso digressivo aproximam do leitor o estudioso, exibindo-o em sua particular humanidade e tornando-o mais acessível ao conhecimento pela surpreendente via da afetividade configurada na digressão.

\begin{abstract}
This paper proposes to analyse Antonio Candido's remembering writings intending to focus on the confluence between memoirs and literary criticism, considered as a particular method of writing, and a adequate way to better comprehend the author and his works.
\end{abstract}

KEYWORDS

Literary criticism, memoirs, memory outcrops, digression, Antonio Candido 


\section{REFERÊNCIAS}

CANDIDO, Antonio. No começo era de fato o verbo. In: LISPECTOR, Clarice. A paixão segundo G. H. Ed. crít. org. por Benedito Nunes. Florianópolis: Archivos da Unesco, 1988. p. XVII-XIX.

CANDIDO, Antonio. Prefácio. In: AZEVEDO, Fernando de (Org.). As ciências no Brasil. 2. ed. Rio de Janeiro: Editora UFRJ, 1994. p. 7-10.

CANDIDO, Antonio. Um poema de Vinicius de Moraes. Teoria e Debate, São Paulo, Fundação Perseu Abramo, ano 14, n. 49, p. 70-71, out.-dez. 2001.

CANDIDO, Antonio. Vários escritos. 4. ed.. Rio de Janeiro: Ouro sobre Azul; São Paulo: Duas Cidades, 2004a.

CANDIDO, Antonio.Observador literário. 3. ed. rev. e ampl. Rio de Janeiro: Ouro sobre Azul, 2004b.

CANDIDO, Antonio. O albatroz e o chinês. Rio de Janeiro: Ouro sobre Azul, 2004c.

CANDIDO, Antonio. A educação pela noite. 5. ed. rev. Rio de Janeiro: Ouro sobre Azul, 2006.

CANDIDO, Antonio. Teresina etc. 3. ed. Rio de Janeiro: Ouro sobre Azul, 2007.

CANDIDO, Antonio. Os parceiros do Rio Bonito: estudo sobre o caipira paulista e a transformação dos seus meios de vida. 11. ed. Rio de Janeiro: Ouro sobre Azul, 2010.

MOURA, Murilo Marcondes de. Circunstâncias e intersecções. Novos Estudos, São Paulo, Cebrap, n. 36, p. 33-39, jul. 1993.

PRADO, Antônio Arnoni. Significação de Recortes. In: AGUIAR, Flávio (Org.). Antonio Candido: pensamento e militância. São Paulo: Humanitas, 1999. p. 61-70. 